\title{
Uric Acid and Pentraxin-3 Levels Are Independently Associated with Coronary Artery Disease Risk in Patients with Stage 2 and 3 Kidney Disease
}

\author{
Mehmet Kanbay ${ }^{a}$ Mustafa Ikizek $^{b}$ Yalcin Solak $^{\mathrm{e}}$ Yusuf Selcoki $^{c}$ Sema Uysal ${ }^{\mathrm{d}}$ \\ Ferah Armutcu $^{d}$ Beyhan Eryonucu ${ }^{c}$ Adrian Covic ${ }^{f}$ Richard J. Johnson ${ }^{g}$ \\ a Division of Nephrology, Departments of Medicine, ${ }^{b}$ Internal Medicine, ${ }^{c}$ Cardiology, and d Biochemistry, \\ Fatih University School of Medicine, Ankara, e Division of Nephrology, Department of Medicine, Meram School of \\ Medicine, Selcuk University, Konya, Turkey; ${ }^{\mathrm{f}}$ Nephrology Clinic, Dialysis and Renal Transplant Center, \\ 'C.I. Parhon' University Hospital, 'Gr. T. Popa' University of Medicine and Pharmacy, lasi, Romania; \\ gDivision of Renal Diseases and Hypertension, University of Colorado-Denver, Denver, Colo., USA
}

\section{Key Words}

Chronic kidney disease $\cdot$ Coronary artery disease $\cdot$ Uric acid • Pentraxin-3

\begin{abstract}
Background and Objectives: Cardiovascular disease is prevalent in chronic kidney disease (CKD). Uric acid is increased in subjects with CKD and has been linked with cardiovascular mortality in this population. However, no study has evaluated the relationship of uric acid with angiographically proven coronary artery disease (CAD) in this population. We therefore investigated the link between serum uric acid (SUA) levels and (i) extent of CAD assessed by the Gensini score and (ii) inflammatory parameters, including C-reactive protein (CRP) and pentraxin-3, in patients with mild-to-moderate CKD. Material and Methods: In an unselected population of 130 patients with estimated glomerular filtration rate (eGFR) between 90 and $30 \mathrm{ml} / \mathrm{min} / 1.73 \mathrm{~m}^{2}$, we measured SUA, serum pentraxin-3, CRP, urinary protein-to-creatinine ratio, lipid parameters and the severity of CAD as assessed by coronary angiography and quantified by the Gensini lesion severity score. Results: The mean serum values for SUA, pentraxin-3 and CRP in the entire study population were 5.5
\end{abstract}

\section{KARGER}

Fax +41613061234 E-Mail karger@karger.ch www.karger.com
(C) 2011 S. Karger AG, Basel

Accessible online at: www.karger.com/ajn $\pm 1.5 \mathrm{mg} / \mathrm{dl}, 6.4 \pm 3.4 \mathrm{ng} / \mathrm{ml}$ and $3.5 \pm 2.6 \mathrm{mg} / \mathrm{dl}$, respectively. The Gensini scores significantly correlated in univariate analysis with gender $(R=-0.379, p=0.02)$, uric acid $(R=$ $0.42, p=0.001)$, pentraxin-3 $(R=0.54, p=0.001), C R P(R=0.29$, $p=0.006)$ levels, eGFR $(R=-0.33, p=0.02)$, proteinuria $(R=$ $0.21, p=0.01)$, and presence of hypertension $(R=0.37, p=$ 0.001 ), but not with smoking status, diabetes mellitus, and lipid parameters. After adjustments for traditional cardiovascular risk factors, only uric acid $(R=0.21, p=0.02)$ and pentraxin-3 $(R=0.28, p=0.01)$ remained significant predictors of the Gensini score. Conclusions: SUA and pentraxin-3 levels are independent determinants of severity of CAD in patients with mild-to-moderate CKD. We recommend a clinical trial to determine whether lowering uric acid could prevent progression of CAD in patients with CKD.

Copyright $\odot 2011$ S. Karger AG, Basel

\section{Introduction}

Chronic kidney disease (CKD) has reached epidemic proportions around the world. In the United States, approximately 8 million adults have stage $3 \mathrm{CKD}$ or greater (defined as glomerular filtration rate (GFR) $<60 \mathrm{ml} /$ 
$\mathrm{min} / 1.73 \mathrm{~m}^{2}$ of body surface area) [1]. Premature cardiovascular disease is the single most common cause of death in patients with end-stage renal disease, accounting for $43 \%$ of all-cause mortality [2]. The increased risk of coronary artery disease (CAD) is also observed in subjects with $\mathrm{CKD}$; for example, subjects with an estimated GFR (eGFR) $<60 \mathrm{ml} / \mathrm{min}$ have a threefold increase in cardiovascular risk [3]. This heightened risk of cardiovascular disease cannot be completely explained by the presence of traditional risk factors such as diabetes mellitus, hypertension, dyslipidemia and smoking [4]. Thus, alternative risk factors, some of which may be unique to CKD and dialysis, have been proposed to explain for this unaccounted increased risk. Proposed nontraditional risk factors include hyperhomocysteinemia, anemia, vascular calcification, volume overload, and endothelial dysfunction [5].

One potentially important risk factor for CAD in subjects with CKD is systemic inflammation. Many patients with CKD have increased blood levels of inflammatory mediators such as the interleukins and tumor necrosis factor- $\alpha$ [6]. C-reactive protein (CRP) was found to correlate both with plaque burden and clinical outcomes [7]. Pentraxin-3 is an emerging inflammatory marker included in the same superfamily with CRP that has been found to correlate with adverse clinical outcomes in patients with CAD [8].

Uric acid has also been reported to stimulate inflammatory responses in vascular cells $[9,10]$. While controversy exists related to the exact role of uric acid in CAD, a recent meta-analysis reported an independent association between adverse cardiac outcomes and increased serum uric acid (SUA) [11]. SUA is frequently increased in CKD patients, with nearly $50 \%$ of subjects starting dialysis being hyperuricemic $[12,13]$. Some studies suggest that lowering uric acid can reduce inflammatory markers such as CRP in both subjects with and without CKD [14-16]. Another study reported that subjects with CKD and hyperuricemia are more likely to suffer cardiovascular mortality [17]. More importantly, Goicoechea et al. [16] reported that the lowering of SUA with allopurinol resulted in a remarkable reduction in cardiovascular events.

We therefore evaluated the role of inflammation, specifically of pentraxin-3 and uric acid levels, in subjects with CKD who underwent coronary angiography to determine if there is a direct relationship between severity of CAD by angiographic criteria and these parameters in this specific population.

\section{Material and Methods}

The study included 216 patients with mild CKD (eGFR between 30 and $90 \mathrm{ml} / \mathrm{min} / 1.73 \mathrm{~m}^{2}$ ) who underwent diagnostic coronary angiography at the Department of Cardiology of the Fatih University Hospital from December 2008 to May 2009. The indications for performing the coronary angiography procedures were based on symptoms, risk factors and results of appropriate noninvasive tests (positive dobutamine stress echocardiography and echocardiography abnormalities confirmed by exercise stress test) - as per guidelines [18]. eGFRs were determined using the Cockcroft-Gault equation immediately prior to the angiography procedure. All patients with an eGFR between 30 and $90 \mathrm{ml} /$ $\mathrm{min} / 1.73 \mathrm{~m}^{2}$ were eligible. Exclusion criteria were: (1) eGFR $>90$ $\mathrm{ml} / \mathrm{min} / 1.73 \mathrm{~m}^{2}$ or GFR $<30 \mathrm{ml} / \mathrm{min} / 1.73 \mathrm{~m}^{2}$; (2) presence of coronary artery bypass graft surgery history; (3) presence of nephrotic syndrome; (4) presence of gout; (5) current use of allopurinol and other hypouricemic or uricosuric treatments, and (6) patients with severe congestive heart failure (New York Heart Association class III-IV). A total of 78 patients were excluded from the study: 43 patients had GFR $\geq 90 \mathrm{ml} / \mathrm{min} / 1.73 \mathrm{~m}^{2}, 11$ patients had GFR $\leq 30 \mathrm{ml} / \mathrm{min} / 1.73 \mathrm{~m}^{2}$ (4 patients were on dialysis); 9 patients had a positive history for coronary artery bypass graft surgery; 9 patients were using allopurinol; 6 patients had class IV congestive heart failure. All 138 remaining patients were included in the study. The study was approved by the Ethical Committee of theFatih University School of Medicine.

Demographic data (age, gender, comorbidities, actual treatment, smoking status, weight, height) were collected before the angiographic procedure from the individual charts in the electronic hospital database. On the morning of the procedure, after a 12-hour fasting period, blood samples were collected, stored, and analyzed by one single laboratory. Serum levels of creatinine, total cholesterol, HDL and LDL subfractions, triglycerides, CRP and SUA were determined using standard measurement techniques. The urinary protein-to-creatinine $(\mathrm{Pr} / \mathrm{Cr}$ ) ratios were determined from samples collected on the morning of the scheduled coronary angiography.

Pentraxin-3 concentrations were quantified using the sandwich ELISA detection system (Hycult Biotech, Uden, The Netherlands) as follows. Samples and standards are incubated in microtiter wells coated with antibodies recognizing human pentraxin-3. Biotinylated tracer antibody binds to captured human pentraxin-3. Streptavidin-peroxidase conjugate binds to the biotinylated tracer antibody, and reacts with the substrate, tetramethylbenzidine. The enzyme reaction is stopped by the addition of oxalic acid. The absorbance at $450 \mathrm{~nm}$ is measured with automatic ELISA reader (ELX 808; BioTek Instruments, USA). In this assay system, the correlation coefficient between the theoretical values and the actual values was 0.99 , and the minimum detection level was about $0.01 \mathrm{ng} / \mathrm{ml}$. The intra-assay standard deviation was always under $10 \%$. The ELISA assay did not cross-react with the short pentraxins CRP and serum amyloid P.

All patients underwent standard coronary angiography assessment performed by the same cardiologist using a common technique. Two experienced physicians blinded to the study analyzed angiograms with a validated quantitative coronary angiographic system (Philips Allura Xper FD10). The extent of CAD was determined using the Gensini score, which is a measure of the extent of myocardial ischemia and is computed by assigning a se- 
Table 1. Demographic and biochemical data of the patients with mild-to-moderate CKD categorized according to the median Gensini score (median Gensini score $=18$ )

\begin{tabular}{|c|c|c|c|c|}
\hline & $\begin{array}{l}\text { Entire group } \\
(\mathrm{n}=138)\end{array}$ & $\begin{array}{l}\text { Gensini score }<16 \\
(\mathrm{n}=69)\end{array}$ & $\begin{array}{l}\text { Gensini score } \geq 16 \\
(\mathrm{n}=69)\end{array}$ & $\mathrm{p}$ value \\
\hline Age, years & $61.2 \pm 6.1$ & $60.7 \pm 6.3$ & $62.6 \pm 7.0$ & 0.38 \\
\hline Male gender, $\mathrm{n}(\%)$ & $75(62.3)$ & $40(58)$ & $46(66.7)$ & 0.2 \\
\hline Hypertension, n (\%) & $85(61.6)$ & $30(43.5)$ & $55(79.7)$ & 0.001 \\
\hline Diabetes mellitus, n (\%) & $28(20.3)$ & $10(14.5)$ & $18(26.1)$ & 0.09 \\
\hline Smoking, n (\%) & $59(42.8)$ & $26(37.7)$ & $33(47.8)$ & 0.23 \\
\hline $\mathrm{eGFR}, \mathrm{ml} / \mathrm{min} / 1.73 \mathrm{~m}^{2}$ & $74.6 \pm 9.1$ & $75.9 \pm 7.6$ & $73.2 \pm 10.2$ & 0.2 \\
\hline Urinary $\mathrm{Pr} / \mathrm{Cr}$ ratio, $\mathrm{g} / \mathrm{l}$ & $0.17 \pm 0.44$ & $0.1 \pm 0.05$ & $0.23 \pm 0.36$ & 0.06 \\
\hline Total cholesterol, mg/dl & $196.8 \pm 48.5$ & $195.1 \pm 42.7$ & $193.4 \pm 53.9$ & 0.9 \\
\hline LDL cholesterol, mg/dl & $121.0 \pm 38.6$ & $122.1 \pm 33.8$ & $119.3 \pm 43.5$ & 0.4 \\
\hline HDL cholesterol, mg/dl & $43.1 \pm 12.6$ & $44.5 \pm 12.2$ & $41.8 \pm 12.9$ & 0.15 \\
\hline Triglycerides, mg/dl & $171.4 \pm 107.4$ & $149.7 \pm 80.2$ & $191.2 \pm 70.4$ & 0.03 \\
\hline $\mathrm{CRP}, \mathrm{mg} / \mathrm{dl}$ & $3.5 \pm 2.6$ & $3.2 \pm 2.0$ & $3.8 \pm 1.0$ & 0.04 \\
\hline Pentraxin-3, ng/ml & $6.4 \pm 3.4$ & $4.9 \pm 2.1$ & $7.2 \pm 3.9$ & 0.001 \\
\hline Uric acid, mg/dl & $5.5 \pm 1.5$ & $5.0 \pm 1.4$ & $6.0 \pm 1.4$ & 0.001 \\
\hline ACE inhibitor, n (\%) & $37(26.8)$ & $11(15.9)$ & $26(37.7)$ & 0.004 \\
\hline $\mathrm{ARB}, \mathrm{n}(\%)$ & $28(20.3)$ & $11(15.9)$ & $17(24.6)$ & 0.2 \\
\hline Statins, n (\%) & $34(24.6)$ & $9(13)$ & $25(36.2)$ & 0.002 \\
\hline
\end{tabular}

verity score to each coronary segment according to the degree of luminal narrowing and its geographic importance [19]. Reduction in the diameter of the lumen, the roentgenographic appearance of concentric lesions, and eccentric plaques were evaluated (the corresponding Gensini scores for reductions of 25, 50, 75, 90, and $99 \%$, and complete occlusion were $1,2,4,8,16$, and 32 , respectively). For each principal vascular segment, a multiplier was assigned according to the functional significance of the myocardial area supplied by this segment: left main coronary artery $\times$ 5 ; proximal segment of the left anterior descending coronary artery $(\mathrm{LAD}) \times 2.5$; proximal segment of the circumflex artery $\times$ 2.5 ; midsegment of the LAD $\times 1.5$; right coronary artery distal segment of the LAD, posterolateral artery, and obtuse marginal artery $\times 1$, and others $\times 0.5$.

\section{Statistical Analyses}

Unless stated otherwise, all data are presented as mean $\pm \mathrm{SD}$. Continuous variables were checked for the normal distribution assumption using the Kolmogorov-Smirnov statistics and those that did not satisfy the criteria were log-transformed to attain normal distribution. The study group was divided into two subgroups based on the median Gensini score. Significant differences between groups were assessed using Student's t test. $\chi^{2}$ was used to test differences in frequency distributions. All potential (physiologically meaningful) determinants of the Gensini score were investigated in a univariate screening procedure, using Pearson's coefficient of correlation test. The nonparametric Spearman $\rho$ coefficient of correlation was used to assess correlations between variables without normal distribution. Significant determinants identified from this analysis were studied in a stepwise multiple regression model using the F statistic. All variables associated with these parameters with a level of significance $<0.1$ were included in the tested model including Framingham risk factors and emerging risk factors. Variables were forced in the model using a stepwise procedure. $\mathrm{p}<0.05$ for the final model was considered as statistically significant. Data were analyzed using the SSPS 15.0 for Windows software (SPSS Inc., Chicago, Ill., USA).

\section{Results}

The mean serum values for SUA, pentraxin-3 and CRP in the entire study population were $5.5 \pm 1.5 \mathrm{mg} / \mathrm{dl}$, $6.4 \pm 3.4 \mathrm{ng} / \mathrm{ml}$ and $3.5 \pm 2.6 \mathrm{mg} / \mathrm{dl}$, respectively (table 1). To better characterize the categorical associations of uric acid and to identify the linear correlates of uric acid and Gensini score, we first performed simple regression analyses between these variables and all variables listed in table 1.

Patients in the category with a higher Gensini score had a higher SUA and pentraxin-3 levels $(\mathrm{p}<0.001)$, a higher prevalence of hypertension $(\mathrm{p}=0.001)$ and higher usage of ACE inhibitors and statins $(\mathrm{p}=0.004$ and $\mathrm{p}=$ 0.002). There were no differences for age, gender, diabetes mellitus, smoking status, LDL and HDL cholesterol, eGFR, and urinary $\mathrm{Pr} / \mathrm{Cr}$ ratio of patients with Gensini score above the median and those below the median (table 1). 
Table 2. Multiple regression models of the Gensini score in mild-to-moderate CKD patients

\begin{tabular}{|c|c|c|c|c|}
\hline & Unadjusted, $\beta$ (p) & Model $1, \beta(p)$ & Model 2, $\beta$ (p) & Model 3, $\beta(p)$ \\
\hline Uric acid, mg/dl & $0.37(0.001)$ & $0.35(0.001)$ & $0.29(0.001)$ & $0.21(0.02)$ \\
\hline Age & & $0.03(0.71)$ & $0.01(0.86)$ & $0.06(0.39)$ \\
\hline Gender & & $-0.22(0.009)$ & $-0.16(0.01)$ & $-0.11(0.34)$ \\
\hline Hypertension & & $0.17(0.04)$ & $0.16(0.08)$ & $0.19(0.07)$ \\
\hline Diabetes mellitus & & $0.04(0.56)$ & $0.01(0.89)$ & $0.03(0.7)$ \\
\hline Total cholesterol & & $0.04(0.56)$ & $0.09(0.29)$ & $0.09(0.41)$ \\
\hline Smoking & & $0.02(0.7)$ & $0.02(0.83)$ & $0.08(0.9)$ \\
\hline GFR & & & $0.09(0.33)$ & $0.21(0.1)$ \\
\hline Proteinuria & & & $0.12(0.16)$ & $0.06(0.5)$ \\
\hline Pentraxin-3, ng/ml & & & & $0.28(0.01)$ \\
\hline $\mathrm{CRP}, \mathrm{mg} / \mathrm{dl}$ & & & & $0.26(0.08)$ \\
\hline
\end{tabular}

The Gensini score values significantly correlated by univariate analysis with gender $(\mathrm{R}=-0.379, \mathrm{p}=0.02)$, uric acid level $(R=0.48, p=0.001)$, pentraxin-3 $(R=0.64$, $\mathrm{p}=0.001)$, CRP $(\mathrm{R}=-0.29, \mathrm{p}=0.006)$, eGFR $(\mathrm{R}=-0.33$, $\mathrm{p}=0.02)$, proteinuria $(\mathrm{R}=0.21, \mathrm{p}=0.01)$, and presence of hypertension $(\mathrm{R}=0.37, \mathrm{p}=0.001)$, but not with the smoking status, presence of diabetes mellitus, and serum lipids (total, LDL and HDL cholesterol levels).

To further analyze the independent contribution of uric acid to the variance of the Gensini score, we performed multiple regression models based on traditional and nontraditional risk factors impacting upon this variable. In the unadjusted analysis, uric acid and the Gensini score were positively correlated (table 2). Adjustment for the full set of Framingham risk factors did not produce any change in the correlation coefficient of the association. Adjustment for emerging risk factors (pentraxin-3 and CRP) substantially reduced the regression coefficient (model 3: $\beta=0.21$; table 2), but did not abolish the association $(\mathrm{p}=0.02)$. Further analysis showed that of the emerging risk factors added to model 3 variables, pentraxin-3 was the sole variable responsible for the attenuation of the strength of the uric acid-Gensini score association.

\section{Discussion}

The main finding of this current study was that SUA levels are independently associated with CAD severity assessed by coronary angiography in patients who had mild-to-moderate CKD. A novel inflammatory marker, pentraxin-3, was also found to be associated with sever- ity of CAD even after adjustment for traditional CAD risk factors.

Uric acid had long been considered as a strong antioxidant [20]. However, recent experimental studies have challenged this view and have shown that uric acid behaves as a prooxidative agent, especially within the cells and under ischemic and hypoxic conditions [21-25]. Clinical and epidemiologic studies have also provided increasing evidence that uric acid may have a contributory causal role in a number of disease states including hypertension and kidney disease [14, 16, 26-28].

The association of elevated SUA with development of atherosclerosis has been the matter of numerous studies to date. Cardiovascular clinical outcomes and extent of atherosclerotic plaques have been two major end points used in numerous studies in this field to date. After the early work of Allard and Goulet [29], which refuted an association between SUA levels and angiographically proven CAD severity, a number of subsequent investigations [30-33] suggested a positive independent association, while others did not [34-36]. Differences in studied populations, study protocols and methods to detect CAD (electron beam CT, coronary angiography) as well as lack of adjustment for inflammatory markers and other novel cardiovascular risk factors may in part account for discrepancies in the results of these studies. A previous meta-analysis reported by Wheeler et al. [37] did not find an independent association of SUA levels with cardiovascular end points. However, a more recent meta-analysis comprising a larger number of randomized controlled studies showed that hyperuricemia may marginally increase the risk of CAD events, independently of traditional CAD risk factors [11]. 
Few studies have examined the relationship of uric acid with cardiovascular disease in patients with CKD. Madero et al. [17] evaluated the relationship of baseline uric acid with all-cause and cardiovascular mortality in 880 subjects from the Modification of Diet in Renal Disease (MDRD) study. Subjects had a mean eGFR of $33 \mathrm{ml} /$ $\mathrm{min} / 1.73 \mathrm{~m}^{2}$ and were followed for a median period of 10 years. Both all-cause and cardiovascular mortality were independently associated with baseline uric acid levels, with every $1-\mathrm{mg} / \mathrm{dl}$ increase of uric acid translating to 17 and $16 \%$ increase in mortality, respectively. More recently, a randomized trial was conducted in which allopurinol was administered for 2 years to 113 subjects with CKD (eGFR $<60 \mathrm{ml} / \mathrm{min} / 1.73 \mathrm{~m}^{2}$ ). In this study, eGFR improved, CRP levels fell and cardiovascular events were reduced in the allopurinol arm [16].

This current study provides additional evidence for a relationship of uric acid with coronary angiographic evidence for CAD in a CKD population. This is important, as cardiovascular death in CKD may represent electrolyte-induced arrhythmias or other causes besides CAD. If uric acid does have a causal role in CAD, it might be by its ability to stimulate the production of oxidized lipids [22] or stimulate inflammation [10, 38]. Uric acid released from injured cells constitutes a major endogenous danger signal that activates the NALP3 inflammasome, which is important in inflammatory lung injury, leading to IL-1 $\beta$ production [39]. Kono et al. [40] also confirmed the role of uric acid as a proinflammatory molecule released from dying cells. Uric acid can also activate MAP kinases as well as nuclear transcription factors associated with the inflammatory response in a variety of cell types $[10,25,38,41]$. Uric acid has also been demonstrated in atherosclerotic plaque [42]. Uric acid is also known to induce small vessel disease in the kidney [43]. The observation that a high uric acid is associated with low coronary blood flow [44], and that a low uric acid is associated with greater coronary flow reserve and hyperemic mean flow velocity in normal subjects, would also be consistent with this possibility [45]. Thus, uric acid may be a harbinger of smoldering inflammation in patients with ischemia or reduced eGFR, and is also independently associated with CAD in the CKD population.

Despite a well-established role in risk stratification in CAD, few studies incorporated inflammatory markers when evaluating association of SUA and CAD burden. Kocaman et al. [32] demonstrated that the number of blood neutrophils and monocytes were independently related with SUA. In the Bezafibrate Infarction Prevention study [46], the combined assessment of SUA and CRP levels provided incremental information for risk stratification of patients with CAD more than each parameter offered alone.

Pentraxin-3 is the prototypic long pentraxin. Both resident and innate immunity cells produce pentraxin-3 in peripheral tissues in response to inflammatory signals and Toll-like receptor activation [47]. Pentraxin-3 is secreted at the site of tissue injury, in contrast to CRP which is secreted by the liver, the vasculature, and by mononuclear cells, and therefore may represent a better measure of the extent of local injury than CRP. In a cohort of 748 patients with ST elevation myocardial infarction, pentraxin-3, measured within the first day from the onset of symptoms along with established markers including CRP, NT-proBNP and troponin T, emerged as the only independent predictor of 3-month mortality [8]. Rolph et al. [48] also showed that advanced atherosclerotic plaques produced pentraxin-3. This group speculated that increased levels of pentraxin-3 in subjects with cardiovascular disease could reflect a protective physiologic response that correlates with the severity of the disease.

Persistent inflammation and oxidative stress start early in the process of CKD [49]. Numerous studies have shown that elevated CRP predicts all-cause and cardiovascular mortality in CKD patients [50]. Pentraxin-3 levels are increased in patients with CKD when compared to healthy controls [51]. Plasma pentraxin-3 levels were also found to be increased in stage 3-4 and stage 5 CKD patients and were associated with the presence of cardiovascular disease and all-cause mortality [52].

Our results demonstrated an association of serum CRP levels with Gensini scores. However, in contrast to pentraxin-3, the association of CRP with Gensini scores disappeared after controlling for traditional cardiovascular risk factors. This suggests that pentraxin- 3 may be superior to CRP as an independent predictor of underlying atherosclerosis in subjects with CKD.

This study has several limitations. First, our study was cross-sectional and therefore conclusions regarding causality are not possible. Second, pentraxin-3, CRP and uric acid were measured only once during the course of the study. The levels of these molecules may change over time in a given person. Thus, it would be more appropriate to evaluate a number of measurements over a given time course. Despite these limitations, our study has strengths as well; we had a sufficient number of patients, and quantified severity of the atherosclerosis with the current gold standard, coronary angiography.

Am J Nephrol 2011;33:325-331 
In conclusion, increased SUA and pentraxin-3 levels are independent determinants of the severity of CAD assessed invasively in patients with mild CKD. These studies raise the possibility that pentraxin- 3 and uric acid may represent important nontraditional risk factors for CAD in the patient with CKD. Large trials aimed at lowering SUA and pentraxin-3 levels should be performed to determine if such treatments slow or halt the progression of atherosclerosis.

\section{Acknowledgement}

R.J.J. is supported by NIH grant HL-68607.

\section{Disclosure Statement}

R.J.J. has patent applications related to lowering uric acid as a means to treat hypertension, reduce the frequency of diabetes, and treat fatty liver. The other authors have no relationships or financial interests with companies related to the findings of this work.

\section{References}

1 Coresh J, Astor BC, Greene T, Eknoyan G, Levey AS: Prevalence of chronic kidney disease and decreased kidney function in the adult US population: Third National Health and Nutrition Examination Survey. Am J Kidney Dis 2003;41:1-12.

-2 Johnston N, Dargie H, Jardine A: Diagnosis and treatment of coronary artery disease in patients with chronic kidney disease: ischaemic heart disease. Heart 2008;94:10801088.

3 Foley RN, Parfrey PS, Sarnak MJ: Clinical epidemiology of cardiovascular disease in chronic renal disease. Am J Kidney Dis 1998; 32(suppl 3):S112-S119.

-4 Cheung AK, Sarnak MJ, Yan G, et al: Atherosclerotic cardiovascular disease risks in chronic hemodialysis patients. Kidney Int 2000;58:353-362.

5 Stenvinkel P, Carrero JJ, Axelsson J, Lindholm B, Heimburger O, Massy Z: Emerging biomarkers for evaluating cardiovascular risk in the chronic kidney disease patient: how do new pieces fit into the uremic puzzle? Clin J Am Soc Nephrol 2008;3:505-521.

-6 Stenvinkel P, Ketteler M, Johnson RJ, et al: IL-10, IL-6, and TNF- $\alpha$ : central factors in the altered cytokine network of uremia - the good, the bad, and the ugly. Kidney Int 2005; 67:1216-1233.

7 Ikeda U: Inflammation and coronary artery disease. Curr Vasc Pharmacol 2003;1:65-70.

$\checkmark 8$ Latini R, Maggioni AP, Peri G, et al: Prognostic significance of the long pentraxin PTX3 in acute myocardial infarction. Circulation 2004;110:2349-2354.

$\checkmark 9$ Kang DH, Han L, Ouyang X, et al: Uric acid causes vascular smooth muscle cell proliferation by entering cells via a functional urate transporter. Am J Nephrol 2005;25:425-433.

10 Kanellis J, Watanabe S, Li JH, et al: Uric acid stimulates monocyte chemoattractant protein-1 production in vascular smooth muscle cells via mitogen-activated protein kinase and cyclooxygenase-2. Hypertension 2003; 41:1287-1293.
11 Kim SY, Guevara JP, Kim KM, Choi HK, Heitjan DF, Albert DA: Hyperuricemia and coronary heart disease: a systematic review and meta-analysis. Arthritis Care Res (Hoboken) 2010;62:170-180.

-12 Lee SM, Lee AL, Winters TJ, et al: Low serum uric acid level is a risk factor for death in incident hemodialysis patients. Am J Nephrol 2009;29:79-85.

-13 Suliman ME, Johnson RJ, Garcia-Lopez E, et al: J-shaped mortality relationship for uric acid in CKD. Am J Kidney Dis 2006;48:761771.

14 Kanbay M, Ozkara A, Selcoki Y, et al: Effect of treatment of hyperuricemia with allopurinol on blood pressure, creatinine clearance, and proteinuria in patients with normal renal functions. Int Urol Nephrol 2007;39: 1227-1233.

15 Ogino K, Kato M, Furuse Y, et al: Uric acidlowering treatment with benzbromarone in patients with heart failure: a double-blind placebo-controlled crossover preliminary study. Circ Heart Fail 2010;3:73-81.

16 Goicoechea M, de Vinuesa SG, Verdalles U, et al: Effect of allopurinol in chronic kidney disease progression and cardiovascular risk. Clin J Am Soc Nephrol 2010;5:1388-1393.

17 Madero M, Sarnak MJ, Wang X, et al: Uric acid and long-term outcomes in CKD. Am J Kidney Dis 2009;53:796-803.

18 Fox K, Garcia MA, Ardissino D, et al: Guidelines on the management of stable angina pectoris: executive summary: The Task Force on the Management of Stable Angina Pectoris of the European Society of Cardiology. Eur Heart J 2006;27:1341-1381.

19 Gensini GG: A more meaningful scoring system for determining the severity of coronary heart disease. Am J Cardiol 1983;51: 606.

20 Ames BN, Cathcart R, Schwiers E, Hochstein P: Uric acid provides an antioxidant defense in humans against oxidant- and radicalcaused aging and cancer: a hypothesis. Proc Natl Acad Sci USA 1981;78:6858-6862.
21 Glantzounis GK, Tsimoyiannis EC, Kappas AM, Galaris DA: Uric acid and oxidative stress. Curr Pharm Des 2005;11:4145-4151.

-22 Sautin YY, Nakagawa T, Zharikov S, Johnson RJ: Adverse effects of the classic antioxidant uric acid in adipocytes: NADPH oxidasemediated oxidative/nitrosative stress. Am J Physiol Cell Physiol 2007;293:C584-C596.

-23 Yu MA, Sanchez-Lozada LG, Johnson RJ, Kang DH: Uric acid: an inducer of oxidative stress and renin-angiotensin system in human vascular endothelial cells. J Hypertens 2010;28:1234-1242.

24 Corry DB, Eslami P, Yamamoto K, Nyby MD, Makino H, Tuck ML: Uric acid stimulates vascular smooth muscle cell proliferation and oxidative stress via the vascular renin-angiotensin system. J Hypertens 2008; 26:269-275.

25 Cheng TH, Lin JW, Chao HH, et al: Uric acid activates extracellular signal-regulated kinases and thereafter endothelin-1 expression in rat cardiac fibroblasts. Int J Cardiol 2008.

26 Mene P, Punzo G: Uric acid: bystander or culprit in hypertension and progressive renal disease? J Hypertens 2008;26:2085-2092.

27 Siu YP, Leung KT, Tong MK, Kwan TH: Use of allopurinol in slowing the progression of renal disease through its ability to lower serum uric acid level. Am J Kidney Dis 2006; 47:51-59.

28 Feig DI, Soletsky B, Johnson RJ: Effect of allopurinol on the blood pressure of adolescents with newly diagnosed essential hypertension. JAMA 2008;300:922-930.

$>29$ Allard C, Goulet C: Serum uric acid: not a discriminator of coronary heart disease in men and women. Can Med Assoc J 1973;109: 986-988.

- 30 Fazlioglu M, Senturk T, Kumbay E, et al: Small arterial elasticity predicts the extent of coronary artery disease: relationship with serum uric acid. Atherosclerosis 2009;202: 200-204. 
>31 Jelic-Ivanovic Z, Memon L, Spasojevic-Kalimanovska V, Bogavac-Stanojevic N, Spasic S: Independent association of high serum uric acid concentration with angiographically defined coronary artery disease. Tohoku J Exp Med 2007;211:369-377.

-32 Kocaman SA, Sahinarslan A, Cemri M, Timurkaynak T, Boyaci B, Cengel A: Independent relationship of serum uric acid levels with leukocytes and coronary atherosclerotic burden. Nutr Metab Cardiovasc Dis 2009;19:729-735.

33 Tuttle KR, Short RA, Johnson RJ: Sex differences in uric acid and risk factors for coronary artery disease. Am J Cardiol 2001;87: 1411-1414.

-34 Gur M, Yilmaz R, Demirbag R, Aksoy N: Relation of serum uric acid levels with the presence and severity of angiographic coronary artery disease. Angiology 2008;59:166-171.

-35 Coutinho Tde A, Turner ST, Peyser PA, Bielak LF, Sheedy PF 2nd, Kullo IJ: Associations of serum uric acid with markers of inflammation, metabolic syndrome, and subclinical coronary atherosclerosis. Am J Hypertens 2007;20:83-89.

36 Lim HE, Kim SH, Kim EJ, et al: Clinical value of serum uric acid in patients with suspected coronary artery disease. Korean J Intern Med 2010;25:21-26.

-37 Wheeler JG, Juzwishin KD, Eiriksdottir G, Gudnason V, Danesh J: Serum uric acid and coronary heart disease in 9,458 incident cases and 155,084 controls: prospective study and meta-analysis. PLoS Med 2005;2:e76.
38 Kang DH, Park SK, Lee IK, Johnson RJ: Uric acid-induced $\mathrm{C}$-reactive protein expression: implication on cell proliferation and nitric oxide production of human vascular cells. J Am Soc Nephrol 2005; 16:3553-3562.

39 Gasse P, Riteau N, Charron S, et al: Uric acid is a danger signal activating NALP3 inflammasome in lung injury inflammation and fibrosis. Am J Respir Crit Care Med 2009;179: 903-913.

40 Kono H, Chen CJ, Ontiveros F, Rock KL: Uric acid promotes an acute inflammatory response to sterile cell death in mice. J Clin Invest 2010;120:1939-1949.

41 Watanabe S, Kang DH, Feng L, et al: Uric acid, hominoid evolution, and the pathogenesis of salt sensitivity. Hypertension 2002;40: 355-360.

42 Suarna C, Dean RT, May J, Stocker R: Human atherosclerotic plaque contains both oxidized lipids and relatively large amounts of $\alpha$-tocopherol and ascorbate. Arterioscler Thromb Vasc Biol 1995;15:1616-1624.

43 Mazzali M, Kanellis J, Han L, et al: Hyperuricemia induces a primary renal arteriolopathy in rats by a blood pressure-independent mechanism. Am J Physiol Renal Physiol 2002;282:F991-F997.

44 Yildiz A, Yilmaz R, Demirbag R, Gur M, Bas MM, Erel O: Association of serum uric acid level and coronary blood flow. Coron Artery Dis 2007;18:607-613.

-45 Erdogan D, Gullu H, Caliskan M, et al: Coronary flow reserve and coronary microvascular functions are strongly related to serum uric acid concentrations in healthy adults. Coron Artery Dis 2006;17:7-14.

-46 Brodov Y, Behar S, Goldenberg I, Boyko V, Chouraqui P: Usefulness of combining serum uric acid and $\mathrm{C}$-reactive protein for risk stratification of patients with coronary artery disease (Bezafibrate Infarction Prevention [BIP] study). Am J Cardiol 2009;104: 194-198.
47 Norata GD, Garlanda C, Catapano AL: The long pentraxin PTX3: a modulator of the immunoinflammatory response in atherosclerosis and cardiovascular diseases. Trends Cardiovasc Med 2010;20:35-40.

48 Rolph MS, Zimmer S, Bottazzi B, Garlanda C, Mantovani A, Hansson GK: Production of the long pentraxin PTX3 in advanced atherosclerotic plaques. Arterioscler Thromb Vasc Biol 2002;22:e10-e14.

49 Shlipak MG, Fried LF, Cushman M, et al: Cardiovascular mortality risk in chronic kidney disease: comparison of traditional and novel risk factors. JAMA 2005;293:17371745.

50 Menon V, Greene T, Wang X, et al: C-reactive protein and albumin as predictors of allcause and cardiovascular mortality in chronic kidney disease. Kidney Int 2005;68: 766-772.

51 Malaponte G, Libra M, Bevelacqua Y, et al: Inflammatory status in patients with chronic renal failure: the role of PTX3 and pro-inflammatory cytokines. Int J Mol Med 2007; 20:471-481

52 Tong M, Carrero JJ, Qureshi AR, et al: Plasma pentraxin-3 in patients with chronic kidney disease: associations with renal function, protein-energy wasting, cardiovascular disease, and mortality. Clin J Am Soc Nephrol 2007;2:889-897. 